\title{
The impact of childhood language difficulties on healthcare costs from 4 to 13 years: Australian longitudinal study
}

\author{
PAULA CRONIN ${ }^{1}$, REBECCA REEVE ${ }^{1,2}$, PATRICIA MCCABE ${ }^{3}$, ROSALIE VINEY $^{1}$ \\ \& STEPHEN GOODALL ${ }^{1}$ \\ ${ }^{1}$ Centre for Health Economics Research and Evaluation (CHERE), University of Technology Sydney, Sydney, \\ Australia, ${ }^{2}$ Centre for Social Impact (CSI), UNSW, Sydney, Australia, and ${ }^{3}$ Faculty of Health Sciences, University \\ of Sydney, Sydney, Australia
}

\begin{abstract}
Purpose: This study investigated the relationship between children's language difficulties and health care costs using the 2004-2012 Longitudinal Study of Australian Children (LSAC).

Method: Language difficulties were defined as scores $>1.25$ SD below the standardised mean on measures of directly assessed receptive vocabulary (4-9 years) and teacher-reported language and literacy (10-13 years). Participant data were individually linked to administrative data, which were sourced from Australia's universal subsidised healthcare scheme (Medicare).

Result: It was found that healthcare costs over each 2-year age band were higher for children with language difficulties than without in the 4-5-year-age bracket (mean difference $1 / 4$ AU $\$ 357,95 \%$ CI $\$ 59, \$ 659$ ), in the 6-7-year-age bracket (mean difference $1 / 4$ AU $\$ 602,95 \%$ CI $\$ 136, \$ 1068$ ) and in the 10-11-year-age bracket (mean difference $1 / 4$ AU $\$ 504,95 \%$ CI $\$ 153$, \$854). Out-of-pocket costs, that is the portion of healthcare costs paid for by the family, were also higher for children with than without language difficulties in the 4-5-year-age bracket (mean difference $1 / 4$ AU\$123, 95\%CI \$46, \$199), in the 6-7year-age bracket (mean difference $1 / 4$ AU $\$ 176$, 95\%CI \$74,278) and in the 10-11-year-age bracket (mean difference $1 / 4$ AU $\$ 79,95 \%$ CI $\$ 6, \$ 152$ ). Medical services accounted for $97 \%$ of total healthcare cost differences.

Conclusion: Overall the findings from this study suggest that language difficulties are associated with increased healthcare costs at key developmental milestones, notably early childhood and as a child approaches the teenage years.
\end{abstract}

Keywords: Language impairment; children; longitudinal

\section{Introduction}

Language difficulties are one of the most common childhood conditions. The prevalence ranges from 7 to $17 \%$ (Law, Boyle, Harris, Harkness, \& Nye, 2000; Reilly et al., 2010; Rice, Slegers, Taylor, \& Zubrick, 2007; Tomblin et al., 1997) with much higher rates in children from disadvantaged backgrounds (Roy \& Chiat, 2013). Language difficulties impact on the day-to-day functioning in many areas of children's lives, including academic achievement, social functioning and overall quality of life (Schoon, Parsons, Rush, \& Law, 2010). There is also evidence that children with language difficulties may have long-term negative outcomes, including decreased educational attainment, work performance and occupational stability (Clegg, Hollis, Mawhood, \& Rutter, 2005; Felsenfeld \& Broen, 1994).

Because of the broad impact and high prevalence, language difficulties are likely to have considerable economic burden for individuals, families and society. As part of a broader enquiry into communication disability, language difficulties have recently been subject to a Senate Enquiry in Australia (Community Affairs References Committee, 2014) whereby they were identified as a priority area. The review concluded that there was an urgent need for the measurement of short, medium and long-term social and economic impacts of speech and language-related disorders (Community Affairs References Committee, 2014).

The long-term costs associated with underemployment and income loss in children with speech, language and communication problems are estimated to be substantial (Ruben, 2000), but little is known about the specific healthcare costs in these populations. The demand for primary care services is likely to be higher in children with language difficulties as they are commonly referred to a wide 
range of services for diagnosis and treatment. These services include speech-language pathology, psychology, paediatrics and early intervention services (Skeat, Gold, Wake, Ukoumunne, \& Reilly, 2011; Skeat et al., 2014). Additionally, there may be downstream costs to the health system due to health conditions that develop as a by-product of the difficulties, such as emotional problems or behavioural difficulties, resulting from underlying co-morbidities such as Attention Deficit Hyperactivity Disorder (ADHD) or due to complex health care needs driven by social disadvantage (Yew \& O'Kearney, 2013).

A small number of Australian studies indicate higher health care expenditure among families with children with language difficulties. For example, Skeat, Gold, Wake, Ukoumunne, \& Reilly (2011) reported both government and out-of-pocket costs for families using the Early Language in Victoria Study (ELVS) (Skeat et al., 2011). This study considered costs at one time point and did not consider other predictors of healthcare utilisation. To date, the longitudinal relationship between health care utilisation and language difficulties has been largely unexplored.

Sciberras et al. (2015) measured the direct healthcare costs associated with language difficulties of children aged between 4 and 8 years using the Longitudinal Study of Australian Children (LSAC) and found that children with language problems compared to those without, have biennial health care expenditures that are on average AU\$160 (95\%CI 63,\$257) higher at age 4-5years (Sciberras et al., 2015). However, in Australia children with language difficulties are more likely to be found in families where English is not the main language spoken (Taylor, Christensen, Lawrence, Mitrou, \& Zubrick, 2013). Therefore, it is unclear how much of the increase in healthcare utilisation is due to the child's language difficulties rather than the child being bilingual. It is possible that simple cross-sectional correlation, without consideration of this confounder may provide biased estimates of the impact of a child's language difficulties on healthcare costs. Additionally, Sciberras et al. (2015) considered healthcare costs defined by the government rebate only, without consideration of the portion of total healthcare costs paid for by the family. The Australian Institute of Health and Welfare (AIHW) estimates that in $2010 / 11,3.2 \%$ of household expenditure related to out-of-pocket healthcare expenses, with considerably higher costs for people with chronic or long-term conditions (Australian Institute of Health and Welfare, 2012). It is likely that the total healthcare costs for a child with language difficulties is considerably higher than the current literature estimates.

The purpose of this study is to explore the longitudinal relationship between language difficulties and healthcare costs, something which has been largely unexplored in the literature to date. By filling this gap, the study advances the literature on children's language and healthcare in Australia. More specifically, this paper draws on four additional years of longitudinal data (up to 13 years). This focuses on the child's progression from early childhood through to teenage years, which represents the age range where key developmental milestones are made. Patient out-of-pocket expenses are calculated to provide a more accurate estimate of the overall healthcare cost. The study utilises longitudinal regression to consider healthcare utilisation over time while simultaneously controlling for attributes of the mother and the household that may influence a child's language acquisition and whether a child seeks medical care.

\section{Method \\ Longitudinal study of Australian children}

The LSAC is a nationally representative, prospective cohort study of children's development in Australia. The LSAC follows two cohorts of children, a Birth (B) cohort and a Kindergarten (K) cohort, each comprising approximately 5000 children. Children were recruited in 2004 and were followed-up every two years. For the purposes of this study, the sample of interest is the $\mathrm{K}$ cohort. In 2004, the $\mathrm{K}$ cohort represented 4983, 4-5-year old children. These children were then followed up at 6-7 years, 8-9 years, 10-11 years and at 12-13 years. At each survey a face-to-face interview with the primary caregiver is administered, supplemented by a mailed survey with the children's teacher and direct assessments of the children. The sample is broadly representative of all Australian children. Full details of the study design have been previously published (Sanson et al., 2002). Healthcare costs were obtained by linkage with participant's Medicare Australia data. Consent for Medicare data linkage was given at Wave 1 and $93 \%$ of the $\mathrm{K}$ cohort consented.

\section{Measurement of language acquisition}

Table I summarises the language measures used in LSAC. The main measures are the short version of the Peabody Picture Vocabulary Test Third Edition (PPVT-III) (2013) (4-9 years), developed specifically for the LSAC and the Academic Rating ScaleLanguage and Literacy (ARS total score) (10-13 years) (Australian Institute of Family Studies, 2010; Dunn \& Dunn, 1997). Both measures are widely used measures of language and communication skills (McLeod \& McKinnon, 2007; Reilly et al., 2014; Sciberras et al., 2015). Children were defined as having language difficulties if their standardised scores were $1.25 \mathrm{SD}$ below the mean on corresponding language measures at each age. At ages 4-5 
Table I. Measures of language acquisition used in LSAC- K cohort 2004-2012.

\begin{tabular}{|c|c|c|c|}
\hline Cohort & Age & Measure & Description \\
\hline \multicolumn{4}{|c|}{ Language acquisition measures } \\
\hline $\mathrm{K}$ & 4-9 & $\begin{array}{l}\text { Peabody Picture Vocabulary test } \\
\text { Third edition (PPVT-III) })^{\text {ab }} \text { - } \\
\text { short version }\end{array}$ & $\begin{array}{l}\text { Australian adapted short version of the PPVT-III (Dunn \& Dunn, 1997) } \\
\text { assesses a child's receptive vocabulary. The PPVT-III is a direct } \\
\text { assessment in which children are asked to select pictures that correspond } \\
\text { to words read out by the examiner. Forty items are administered, } \\
\text { consisting of } 20 \text { core items and } 10 \text { base and ceilings items. Raw scores are } \\
\text { converted to scaled scores. This adapted version has a reliability of } 0.76 \\
\text { (Rothman, 2003). }\end{array}$ \\
\hline $\mathrm{K}$ & $10-13$ & $\begin{array}{l}\text { Academic rating scale - Language } \\
\text { and literacy }{ }^{\mathrm{ab}} \text {. }\end{array}$ & $\begin{array}{l}\text { A 9-item teacher completed questionnaire of reading and comprehension } \\
\text { (e.g. Conveys ideas clearly, understands and interprets text, reads and } \\
\text { comprehends). Teachers report the proficiency of the child on a } 5 \text { point } \\
\text { scale (Not yet; Beginning; In progress; Intermediate: Proficient) Aims to } \\
\text { rate a child's language and literacy skills in relation to other children at the } \\
\text { same grade level known by the teacher (Australian Institute of Family } \\
\text { Studies, 2010). This measure has validity to assess developmental skill } \\
\text { consistent with early literacy acquisition (Bishop \& Adams, 1990; } \\
\text { Buil-Legaz, Aguilar-Mediavilla, \& Rodríguez-Ferreiro, 2016; Leitao \& } \\
\text { Fletcher, 2004; Lewis et al., 2015) }\end{array}$ \\
\hline
\end{tabular}

Supplementary measures

K $\quad 4-7 \quad$ Parents Evaluation of

Developmental Status (PEDS)

Parent reported question is concern about how the child understands what the parent says (receptive). (No; a little; Yes) (Australian Institute of Family Studies, 2010)

${ }^{a}$ Children were defined as having language difficulties at each age if their standardised language scores were $51.25 \mathrm{SD}$ below the mean.

${ }^{b}$ Language scores were standardised using the transformation of continuous raw scores to Z-scores at each age group.

years and 6-7 years the Parents Evaluation of Developmental Status (PEDS) for receptive and expressive language is also available. This second measure has been used in the literature (McLeod \& Harrison, 2009) and allowed us to examine whether healthcare cost patterns were consistent when using alternative measures of language.

\section{Healthcare costs}

Healthcare in Australia is funded through a combination of state and federal government funding $(70 \%)$, private insurance $(13 \%)$ and individual outof-pocket expenses (17\%) (Australian Institute of Health and Welfare (AIHW), 2013). The federal government funds a public insurance scheme for all the Australians (Medicare) to provide subsidised access to medical services provided in the community (Medicare Benefits Scheme (MBS)), free public hospital treatment and subsidised access to pharmaceuticals (Pharmaceutical Benefits Scheme (PBS)) (Tier 1). In addition, a second tier includes privately funded health insurance that covers private hospital services and a portion of allied health services. Copayments (portion of the total service fee payable by the patient) apply to many services.

The outcome variables considered in the analysis include total healthcare and out-of-pocket costs Total healthcare costs were obtained by linkage with Australian Medicare data. Biennial (2-year) costs for each child were calculated over a 10-year period, that is, calendar years, from 2003 to 2004, 2005 to 2006, 2007 to 2008, 2009 to 2010 and 2011 to 2012. Medical services (MBS) and pharmaceutical (PBS) costs were combined to report total healthcare costs. We report on out-of-pocket costs as the portion of total healthcare costs that are paid for by the family on behalf of the child. Costs in the Medicare linked dataset are reported at an item level and include the MBS/PBS subsidy or government rebate portion of the total service fee only. The total service fee was then determined by the sum of the MBS/PBS subsidy and a calculated co-payment. Total healthcare costs were calculated as the sum of all total service fees. Total out-of-pocket costs were calculated as the sum of all co-payments. Overall, out-of-pocket costs represent approximately $26 \%$ of the total healthcare costs in the analysis. The AIHW estimates that individual out-of-pocket costs make up $28 \%$ of the total federal government expenditure. Given that the sample of interest is children, whereby there is likely to be a higher rate of bulk billing, the calculated out-of-pocket cost is consistent with the literature. (Australian Institute of Health and Welfare (AIHW), 2013). Full details on the assumptions and methods used to calculate total service fees and co-payments are located in Supplementary material.

In terms of medical services that are particularly relevant to children with language difficulties, under the current policy Medicare provides a subsidy towards unlimited visits to general practitioners, specialist physicians (including paediatrics). For access to Medicare subsidies for speech-language pathology, other allied health services and psychology the primary care physician nominates the number of services, up to a maximum of five per calendar year (Australian Government Department of Health, 2015). State-funded community or educationally based providers and private non-referred health services are not accounted for in these analyses. The AIHW estimates that approximately $10 \%$ of all primary health care costs (including referred specialist services) are from community 
health services and a further $4 \%$ are from private non-referred health services (Australian Institute of Health and Welfare (AIHW), 2013).

\section{Descriptive statistics}

Table II shows the prevalence of language difficulties amongst different demographic groups in the Australian population. Approximately 9\% of children aged between 4 and 13 years were defined as having language difficulties between 2004 and 2012. Prevalence estimates varied according to sociodemographic characteristics of the children and their families. Language difficulties were more prevalent among males $(8.3 \%)$, when compared to females $(6.4 \%)$ and among children in the lowest family income quintile $(17.1 \%)$, compared to the highest $(3.7 \%)$. Prevalence of language difficulties was higher in children whose mothers spoke a language other than English at home (14.1\%) when compared to English speakers (7.5\%), in indigenous $(19.7 \%)$ compared to non-indigenous $(8 \%)$ children, those children with long-term medical conditions $(11.3 \%)$ compared to without $(7.6 \%)$ and those with average or below health status
(11.3\%) compared to children in excellent health (7.1\%). Language difficulties were negatively associated with the presence of private health insurance $(4.9 \%)$.

\section{Measures}

The summary statistics of the explanatory variables considered in the analyses are shown in Panel BPanel D, Table III below. These statistics are reported biennially (2 years) from 2004 to 2005, 2006 to 2007, 2008 to 2009, 2010 to 2011 and 2012 to 2013. The summary statistics of the outcome variables are shown in Panel A, Table III (see Supplementary material for detailed definitions). These statistics are reported biennially (2 years) from 2003 to 2004,2005 to 2006,2007 to 2008, 2009 to 2010 and 2011 to 2012. In a two-year period a child in the $\mathrm{K}$ cohort has on average AU \$1607 (SD \$2467) of healthcare expenditure, of which AU\$306 (SD \$594) is an out-of-pocket expense.

Child characteristics were used as explanatory variables in the model to determine which types of characteristics contribute to health service

Table II. Prevalence of language difficulties in Australia (reported biennially (2 years)).

\begin{tabular}{|c|c|c|c|}
\hline & Total sample ${ }^{\mathrm{a}}$ & No. $\%$ & with language difficulties \\
\hline \multicolumn{4}{|l|}{ Panel $A^{\mathrm{a}}$} \\
\hline \multicolumn{4}{|l|}{ Language difficulties } \\
\hline $4 / 5$ years & 4093 & 340 & 8.3 \\
\hline $6 / 7$ years & 4384 & 278 & 6.3 \\
\hline $8 / 9$ years & 4409 & 408 & 9.3 \\
\hline $10 / 11$ years & 3712 & 451 & 12.1 \\
\hline $12 / 13$ years & 3716 & 474 & 12.8 \\
\hline \multicolumn{4}{|l|}{ Panel B } \\
\hline \multicolumn{4}{|l|}{ Gender } \\
\hline Female & 2249 & 144 & 6.4 \\
\hline Male & 2357 & 196 & 8.3 \\
\hline \multicolumn{4}{|c|}{ Mother speaks another language at home } \\
\hline NESB & 714 & 147 & 14.1 \\
\hline English speaking & 3892 & 193 & 7.5 \\
\hline \multicolumn{4}{|l|}{ Child is Indigenous } \\
\hline Indigenous & 172 & 21 & 19.7 \\
\hline Non-indigenous & 4434 & 319 & 8.0 \\
\hline \multicolumn{4}{|l|}{ Household income $^{\mathrm{a}}$} \\
\hline Lowest & 667 & 114 & 17.1 \\
\hline Quintile 2 & 994 & 94 & 9.5 \\
\hline Middle & 888 & 62 & 7.0 \\
\hline Quintile 4 & 705 & 31 & 4.4 \\
\hline Highest & 537 & 20 & 3.7 \\
\hline \multicolumn{4}{|l|}{ Private health insurance } \\
\hline Private health insurance & 2135 & 104 & 4.9 \\
\hline Uninsured & 2463 & 286 & 11.6 \\
\hline \multicolumn{4}{|l|}{ Child's global health status ${ }^{a}$} \\
\hline Excellent health & 2369 & 169 & 7.1 \\
\hline Very good/good health & 1246 & 117 & 9.4 \\
\hline Average and below health & 478 & 54 & 11.3 \\
\hline \multicolumn{4}{|l|}{ Long-term medical conditions ${ }^{\mathrm{a}}$} \\
\hline No medical conditions & 3281 & 248 & 7.6 \\
\hline Medical conditions & 812 & 92 & 11.3 \\
\hline Sample size & 4606 & & \\
\hline
\end{tabular}

NESB: Non-English speaking background; K: kindergarten.

${ }^{\text {a }}$ Sample is subject to missing observations. Prevalence is calculated on a total sample size of non-missing observations only.

${ }^{\mathrm{b}}$ The sample is indicative of wave 1 only, when participants are 4-5 years old.

See Supplementary material for the definition of variables and description of the sample.

Sources: The 2004, 2006, 2008, 2010 and 2012 Longitudinal Study of Australian Children (K cohort). 


\begin{tabular}{|c|c|c|c|}
\hline \multirow[b]{2}{*}{ Variable } & \multirow[b]{2}{*}{ Measurement } & \multicolumn{2}{|c|}{ K cohort } \\
\hline & & Mean & SD \\
\hline \multicolumn{4}{|l|}{ PanelA. Outcome variables } \\
\hline Healthcare costs & $\begin{array}{l}\text { Healthcare costs } 1 / 4 \text { Medical Services (MBS)+ } \\
\text { Pharmaceuticals(PBS)+ Hospital Costs }\end{array}$ & 1607 & 2467 \\
\hline Out-of-pocket costs (OOP) & OOP $1 / 4$ Healthcare costs - Co-payments & 306 & 594 \\
\hline \multicolumn{4}{|l|}{ Panel B. Child's characteristics } \\
\hline Language difficulties ${ }^{\mathrm{a}}$ & $11 \frac{1}{4} \mathrm{Yes}, 01 / 4 \mathrm{No}$ & 0.09 & 0.29 \\
\hline Missing language difficulties ${ }^{\mathrm{b}}$ & $11 \frac{1}{4}$ Yes, $01 / 4$ No & 0.01 & 0.12 \\
\hline Receptive language concern ${ }^{\mathrm{a}}$ & $1 \frac{1}{4}$ Yes, $01 / 4$ No & 0.10 & 0.30 \\
\hline Expressive language concern $^{\mathrm{c}}$ & $11 \frac{1}{4}$ Yes, $01 / 4$ No & 0.18 & 0.39 \\
\hline \multirow[t]{4}{*}{ Long-term medical conditions } & $11 \frac{1}{4}$ Yes, $01 / 4$ No & & \\
\hline & Language plus 1 other condition & 0.03 & 0.16 \\
\hline & 1 condition other than language & 0.08 & 0.27 \\
\hline & 2 or more conditions other than language & 0.02 & 0.29 \\
\hline Child is Indigenous & $\begin{array}{l}11 \frac{1}{4} \text { Yes, } 01 / 4 \text { No Includes Aboriginal and } \\
\text { Torres Strait Islander }\end{array}$ & 0.04 & 0.19 \\
\hline \multirow[t]{4}{*}{ Child's global health status } & Ordered 1:5 derived 11/4 Yes, 01/4 No. & & \\
\hline & Excellent health & 0.46 & 0.50 \\
\hline & Very Good/Good health & 0.31 & 0.46 \\
\hline & Average and below Health & 0.23 & 0.42 \\
\hline \multirow[t]{5}{*}{ Wave } & Wave 1 (child aged 4-5 years) & 0.20 & 0.40 \\
\hline & Wave 2 (child aged 6-7 years) & 0.20 & 0.40 \\
\hline & Wave 3 (child aged $8-9$ years) & 0.20 & 0.40 \\
\hline & Wave 4 (child aged $10-11$ years) & 0.20 & 0.40 \\
\hline & Wave 5 (child aged $12-13$ years) & 0.20 & 0.40 \\
\hline \multicolumn{4}{|l|}{ Panel C. Mother's characteristics } \\
\hline Mother speaks language other than English at home & $11 \frac{1}{4}$ Yes, $01 / 4$ No & 0.15 & 0.36 \\
\hline Mother has completed Year 12 & $11 / 4$ Yes, $01 / 4$ No & 0.58 & 0.49 \\
\hline Mother has a long term medical condition & $11 / 4$ Yes, $01 / 4 \mathrm{No}$ & 0.09 & 0.29 \\
\hline $\begin{array}{l}\text { Mother's relative has suffered a serious illness, injury } \\
\text { or assault in the last year }\end{array}$ & $1 \frac{1}{4}$ Yes, $01 / 4$ No & 0.14 & 0.34 \\
\hline Mother has a resident partner & $11 / 4$ Yes, $01 / 4$ No & 0.83 & 0.37 \\
\hline \multicolumn{4}{|l|}{ Panel D. Household characteristics } \\
\hline Household income & Annual gross household income equivalised & 47223 & 37894 \\
\hline Missing household income & $1 \frac{1}{4}$ Yes, $01 / 4$ No & 0.05 & 0.21 \\
\hline Mother receives Carer's benefits & $11 \frac{1}{4}$ Yes, $01 / 4$ No & 0.04 & 0.19 \\
\hline Private health Insurance & $1 \frac{1}{4} \mathrm{Yes}, 01 / 4 \mathrm{No}$ & 0.50 & 0.95 \\
\hline Number of siblings the child has & Range $0-11$ & 1.59 & 1.08 \\
\hline \multicolumn{2}{|l|}{ Number of observations (child * year) } & 23021 & \\
\hline \multicolumn{2}{|c|}{ Number of observations with no missing values for household income } & 21908 & \\
\hline \multicolumn{2}{|c|}{ Number of observations with no missing values for language difficulties } & 20314 & \\
\hline \multicolumn{2}{|c|}{ Unique number of observations (child) } & 4606 & \\
\hline
\end{tabular}

K: kindergarten cohort; MBS: medical benefits scheme; PBS: pharmaceutical benefits scheme; SD: standard deviation.

${ }^{\mathrm{a}}$ Children are excluded from the language difficulties group if they reported other long-term medical conditions; ${ }^{\mathrm{b}} \mathrm{Refer}$ to Supplementary material for assumptions about missing observations; ${ }^{c}$ Receptive and expressive language measures available from ages 4 to 7 years. These measures are used in a supplementary analysis only.

Note: Refer to Supplementary material for the definitions of the variables and the description of the sample.

Sources: The 2004; 2006, 2008, 2010 and 2012 Longitudinal Study of Australian Children (K cohorts).

utilisation and healthcare cost. Mothers and household characteristics were used as explanatory variables to test whether particular attributes of the mother or household, influence whether a child seeks medical care. Approximately $15 \%$ of the mothers speak a language other than English at home and $9 \%$ of the mothers have a long-term medical condition. Total household gross income, which was defined to be the sum of maternal income, resident partner's income, and the income of any other employed person who is present in the household and is then equivalised to account for the number of people in the household, was AU \$47223 (SD \$37894) (in 2014 prices). Approximately $4 \%$ of the sample received the Carer's Benefit: an income supplement that is paid to carers who provide additional daily care and attention for someone with a long-term disability or medical condition.

The explanatory variable of interest is the variable indicating whether a child has language difficulties (Panel B, Table III). This is based on a number of child language measures in the LSAC (Table I) and has a prevalence of $9 \%$, when defined in terms of the main language measures.

\section{Final sample for analysis}

From the original sample of 4983 children, Medicare records were linked for 4606 children $(92.3 \%)$. Nine observations were excluded as healthcare cost outliers, defined by individuals with costs over AU\$50000 in any two-year period. This criterion is consistent with the literature (Sciberras et al., 2015). T-tests were used to 
Table IV. Total 2-year healthcare costs per child by language difficulty status and age: Australia 2003-2012.

\begin{tabular}{|c|c|c|c|c|c|c|}
\hline \multirow[b]{2}{*}{ Age } & \multicolumn{2}{|c|}{ Mean } & \multicolumn{4}{|c|}{ Mean difference $(95 \% \mathrm{CI})$} \\
\hline & $\begin{array}{r}\text { Language } \\
\text { difficulty }\end{array}$ & $\begin{array}{c}\text { No language } \\
\text { difficulty }\end{array}$ & 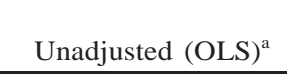 & $\begin{array}{c}\text { OLS + explanatory } \\
\text { variables }^{\mathrm{b}}\end{array}$ & $\begin{array}{r}\text { Adj } \\
\text { explan }\end{array}$ & $\begin{array}{l}\text { sted }(\mathrm{FE})+ \\
\text { tory variables }^{\mathrm{c}}\end{array}$ \\
\hline $\mathrm{K}$ cohort & 1 & 2 & 3 & 4 & & 5 \\
\hline 4-5 years & 1878 & 1561 & {$[23,610]$} & $534 * * \quad[264,803]$ & $357 *$ & {$[59,659]$} \\
\hline $6-7$ years & 1833 & 1539 & {$[-225,812]$} & $541 *[43,1039]$ & $602 *$ & {$[136,1068]$} \\
\hline $8-9$ years & 1376 & 1613 & {$[-502,27]$} & $-33[-310,244]$ & 58 & {$[-200,315]$} \\
\hline $10-11$ years & 2276 & 1750 & {$[99,954]$} & $581 * * \quad[189,972]$ & $504 * *$ & {$[153,854]$} \\
\hline $12-13$ years & 2198 & 2341 & {$[-495,209]$} & $53[-273,379]$ & 48 & {$[-250,346]$} \\
\hline
\end{tabular}

Biennial (2-year) costs in 2014 \$AUD, rounded to the nearest dollar, $95 \%$ confidence intervals $(\mathrm{CI})$ in parentheses, ${ }^{+} p 50.10 ;{ }^{*} p 50.05$; $* * p 50.01$.

OLS: ordinary least squares; FE: fixed effects.

${ }^{a}$ Logistic regression (OLS) includes explanatory variables for a child language difficulties at 4-5 years, 6-7 years, 8-9 years, 10-11 years, 12-13 years interacted with time (Wave1, Wave 2, Wave 3, Wave 4, Wave 5) and weighted for attrition.

${ }^{\mathrm{b}}$ Logistic regression (OLS) includes explanatory variables for a child with language difficulties at 4-5 years, 6-7 years, 8-9 years, 10-11 years, 12-13 years interacted with time (Wave1, Wave 2, Wave 3, Wave 4, Wave 5), three other variables for the child; whether the child is Aboriginal or Torres Strait Islander, the health status of the child (excellent, very good/good and average/below) and three variables for long-term health conditions the child has (language plus one long-term condition, one long-term condition without language, two or more long-term conditions without language difficulties). Mothers characteristics include the mothers educational attainment (mothers who $\mathrm{did} /$ did not complete year 12), one variable indicating mothers health status (long-term medical conditions), one variable indicating health shocks (mother's relatives who suffered serious injury, assault or illness) and one variable indicating if the mother has a resident partner. Household characteristics include the number of siblings the child has, household income levels (equivalised and quintiles determined), whether the mother receives a carer's allowance, a variable for the child's health insurance status and four variables for observations in Wave 2 to Wave 5 (biennial waves form 2004-2012). Model is weighted for attrition.

${ }^{c}$ Fixed affects regression includes explanatory variables as defined in b. Model is weighted for attrition.

compare the differences of baseline characteristics between the full LSAC sample and the reduced Medicare-linked sample. No significant differences were observed (results available on request).

\section{Analysis}

Fixed effects regression was used to explore the association between healthcare costs and language difficulties from 4 to 13 years. This method improves on cross-sectional analysis as it provides longitudinal estimates that take into account observed and unobserved confounders of healthcare and language that are time invariant. That is, this type of regression analysis implicitly controls for the effects of particular attributes of the mother or household that might influence whether a child seeks medical care, as well as influencing the child's opportunities to develop language, as long as they do not vary over time. For example, a child whose mother speaks a language other than English at home or the indigenous status of the child. While a possibility of biases due to unobserved time-variant confounders remains, results based on this type of regression are more reliable than those based on cross-sectional analysis. In Table IV, columns 1 and 2 show the mean unadjusted healthcare costs for children with and without language difficulties. In Table IV, column 3 shows the unadjusted (crosssectional) mean difference in healthcare costs for children with and without language difficulties, across each age-group, without controlling for any explanatory variables. Column 4 repeats the analysis from column 3 while simultaneously controlling for the explanatory variables outlined in Table III (OLS+explanatory variables). In Table IV, column 5 shows the adjusted mean difference in healthcare for children with and without language difficulties using fixed effects regression analysis while simultaneously controlling for the explanatory variables outlined in Table III. The analysis was conducted using STATA 14 SE (College Station, TX).

\section{Result}

Table IV shows the estimates for 2-year total healthcare costs for a child with language difficulties. The cross-sectional results (column 3) showed that a child with language difficulties, compared to a child without, had higher healthcare costs between 4-5 years and 10-11 years of age. Once explanatory variables were simultaneously controlled for in the analysis (Table IV, column 4 and 5) this brought about significant changes in the estimates. In this analysis statistically significant differences were found in total healthcare costs for children with language difficulties, compared to those without, at age 4-5 years AU\$534 (95\%CI \$264, \$803), at 6-7 years AU\$541 $(95 \%$ CI \$43, \$1039) and at age 1011 years AU\$581 (95\%CI \$189, \$972). The results of the longitudinal fixed effects methods showed that 2-year healthcare costs for children with language difficulties, when compared to those without, were AU\$357 (95\%CI \$59, \$659) higher at age 4-5 years, AU\$602 (95\%CI \$136, \$1068) higher at age 6-7years and AU\$504 (95\%CI \$153, \$854) higher at age $10-11$ years.

${ }^{1}$ Interactions with time are included to capture how the mean effect varies by age. That is, the effect of language difficulties on healthcare costs is shown to significantly differ at 4-5 years, 6-7 years and 10-11years. 
Table V. Total 2-year out-of-pocket costs per child by language difficulties status and age: Australia $2003-2012$.

\begin{tabular}{|c|c|c|c|c|c|c|}
\hline \multirow[b]{2}{*}{ Age } & \multicolumn{2}{|c|}{ Mean } & \multicolumn{4}{|c|}{ Mean difference $(95 \% \mathrm{CI})$} \\
\hline & $\begin{array}{r}\text { Language } \\
\text { difficulty }\end{array}$ & $\begin{array}{c}\text { No language } \\
\text { difficulty }\end{array}$ & Unadjusted $^{\mathrm{a}}$ & $\begin{array}{c}\text { OLS + explanatory } \\
\text { variables }^{\text {b }}\end{array}$ & $\begin{array}{r}\text { Ad } \\
\text { explar }\end{array}$ & $\begin{array}{l}\text { ed }(\mathrm{FE})+ \\
\text { ry variables }\end{array}$ \\
\hline $\mathrm{K}$ cohort & 1 & 2 & 3 & 4 & & 5 \\
\hline $4-5$ years & 290 & 266 & $23 \quad[-34,80]$ & $106^{* *} \quad[50,161]$ & $123 * *$ & {$[46,199]$} \\
\hline $6-7$ years & 288 & 279 & $9 \quad[-95,113]$ & $111^{*} \quad[8,213]$ & $176^{* * *}$ & {$[74,278]$} \\
\hline $8-9$ years & 213 & 302 & $-88 * * \quad[-136,-40]$ & $-13 \quad[-63,37]$ & 25 & {$[-33,83]$} \\
\hline $10-11$ years & 321 & 340 & $-19 \quad[-86,48]$ & $41 \quad[-25,107]$ & $79^{*}$ & {$[6,152]$} \\
\hline $12-13$ years & 383 & 488 & $-106^{*} \quad[-188,-23]$ & $-23 \quad[-100,54]$ & -21 & {$[-94,51]$} \\
\hline
\end{tabular}

Biennial (2-year) costs in 2014 \$AUD, rounded to the nearest dollar, $95 \%$ confidence intervals (CI) in parentheses, $+p 50.10 ; * p 50.05$; $* * p 50.01$.

OLS: ordinary least squares; FE: fixed effects.

${ }^{a}$ Logistic regression (OLS) includes explanatory variables for a child language difficulties at 4-5years, 6-7years, 8-9years, 10-11 years, 1213 years interacted with time (Wave1, Wave 2, Wave 3, Wave 4, Wave 5) and weighted for attrition.

${ }^{\mathrm{b}}$ Logistic regression (OLS) includes explanatory variables for a child with language difficulties at 4-5 years, 6-7 years, 8-9 years, 10-11 years, 12-13 years interacted with time (Wave1, Wave 2, Wave 3, Wave 4, Wave 5), three other variables for the child; whether the child is Aboriginal or Torres Strait Islander, the health status of the child (excellent, very good/good and average/below) and three variables for long-term health conditions the child has (language plus long-term condition, one long-term condition without language, two or more long-term conditions without language). Mothers characteristics include the mothers educational attainment (mothers who did/did not complete year 12), one variable indicating mothers health status (long-term medical conditions), one variable indicating health shocks (mother's relatives who suffered serious injury, assault or illness) and one variable indicating if the mother has a resident partner. Household characteristics include the number of siblings the child has, household income levels (equivalised and quintiles determined), whether the mother receives a carer's allowance, a variable for the child's health insurance status and four variables for observations in Wave 2 to Wave 5 (biennial waves form 2004-2012). Model is weighted for attrition.

${ }^{c}$ Fixed affects regression includes explanatory variables as defined in $b$.

The portion of healthcare costs paid by the family on behalf of the child (out-of-pocket costs) was also significantly higher for children with language difficulties, compared to those without once explanatory variables were considered. Based on the cross-sectional results with explanatory variables, (Table V, columns 4) the difference in total 2-year out-of-pocket costs for children with than without language difficulties was AU\$106 (95\%CI \$50, \$161) at 4-5 years and AU\$111 (95\%CI \$8, $\$ 213$ ) at 6-7years. Once longitudinal fixed effects models were considered, statistically significant differences were found in total 2-year out-of-pocket costs for children with language difficulties, compared to those without at age 4-5 years AU\$123 (95\% CI \$46, \$199), at age 6-7 years AU\$176 (95\% CI \$74, \$278) and at age 10-11 years AU\$79 (95\% CI \$6, \$152).

Comparison of healthcare costs by type of health service (Table VI) showed that medical services accounted for $97 \%$ of the total healthcare cost differences for children with language difficulties, compared to those without, which was largely driven by general practise visits, speech-language pathology and other allied health services. Medical service costs for children with language difficulties, compared to those without, were AU\$381 (95\%CI \$89, $\$ 674$ ) higher in the 4-5 year age bracket, AU\$603 (95\%CI \$160, \$1047) higher in the 6-7 age bracket and AU\$455 (95\%CI \$131, \$778) higher in the 1011 year age bracket (Table VI, Column 2). Pharmaceutical costs in the 10-11 year age bracket accounted for the remaining $3 \%$ of the total healthcare costs differences (mean difference $1 / 4$ AU\$49, (95\%CI \$32, \$130)) (Table VI, column 3).

In a supplementary analysis an alternative measure of language difficulties was used to test the consistency of the results. In this supplementary analysis the explanatory variable of interest was based on a language measure in the LSAC indicating whether a mother has concern for her child's receptive or expressive language (Table I). This variable was asked when the child was aged 4-5 years and then 2 years later, at 6-7 years and has been used to identify children's language in previous studies (McLeod \& Harrison, 2009). The prevalence of receptive language concern in children aged between 4 and 7 years is largely consistent with the prevalence identified using the main language measures $(9 \%)$. The fixed effects regression model can only be computed for the waves where the measure is observed which in this case is wave 1 and wave 2 , when the child is 4-5 years and 6-7 years. The model simultaneously controls for the explanatory variables outlined in Table III. Statistically significant differences were found in total healthcare costs for children with language difficulties, compared to those without, at age 4-5 years AU\$264 (95\%CI $\$ 16, \$ 512)$. These results are consistent with the results identified by the main language measures in Table IV.

\section{Discussion}

This paper has investigated the cross-sectional and longitudinal relationships between healthcare costs and children's language difficulties using the 20042012 LSAC. The first set of findings is that there is a consistently positive relationship between children's language difficulties and their healthcare utilisation in both cross-sectional and longitudinal analyses once background characteristics are accounted for. Children with language difficulties aged 4-7 years, 6-7 years and 10-11 years are more likely to have 
Table VI. Total 2-year medical services (MBS) and Pharmaceutical (PBS) costs \$AUD per child by language difficulty status.

\begin{tabular}{lcccccc}
\hline \multicolumn{7}{c}{ Mean difference $(95 \% \mathrm{CI})$} \\
\hline Age & \multicolumn{7}{c}{ Total healthcare } & \multicolumn{2}{c}{ Medical services ${ }^{\mathrm{a}, \mathrm{b}}$} & \multicolumn{2}{c}{ Pharmaceuticals ${ }^{\mathrm{a}, \mathrm{b}}$} \\
\hline K cohort & 1 & 2 & 3 & & & \\
4-5 years & $357^{*}$ & {$[59,659]$} & $381^{*}$ & {$[89,674]$} & -23 & {$[-94,49]$} \\
6-7 years & $602^{*}$ & {$[136,1068]$} & $603^{* *}$ & {$[160,1047]$} & -1 & {$[-92,89]$} \\
8-9 years & 58 & {$[-200,315]$} & 53 & {$[-189,295]$} & 5 & {$[-56,65]$} \\
$10-11$ years & $504^{* *}$ & {$[153,854]$} & $455^{* *}$ & {$[131,778]$} & $49^{*}$ & {$[32,130]$} \\
$12-13$ years & 48 & {$[-250,346]$} & 63 & {$[-219,346]$} & -15 & {$[-72,42]$} \\
\hline
\end{tabular}

Biennial (2-year) costs in 2014 \$AUD, rounded to the nearest dollar, 95\% confidence intervals (CI) in parentheses, *p50.05,**p50.01.

${ }^{a}$ Medical services include hospital attendances.

${ }^{b}$ Fixed affects regression includes explanatory variables for a child with language difficulties at 4-5 years, 6-7 years, 8-9 years, 10-11 years, 12-13 years interacted with time (Wave1, Wave 2, Wave 3, Wave 4, Wave 5), three other variables for the child; whether the child is Aboriginal or Torres Strait Islander, the health status of the child (excellent, very good/good and average/below) and three variables for long-term health conditions the child has (language difficulties plus one long-term condition, one longterm condition without language, two or more long-term conditions without language difficulties). Mothers characteristics include the mothers educational attainment (mothers who did/did not complete year 12), one variable indicating mothers health status (long-term medical conditions), one variable indicating health shocks (mother's relatives who suffered serious injury, assault or illness) and one variable indicating if the mother has a resident partner. Household characteristics include the number of siblings the child has, household income levels (equivalised and quintiles determined), whether the mother receives a carer's allowance, a variable for the child's health insurance status and four variables for observations in Wave 2 to Wave 5 (biennial waves form 2004-2012).

increased healthcare utilisation, relative to children aged 8-9 years or 12-13 years. The demand for additional medical services at 4-5 years is consistent with the identification of language difficulties during pre-school years or as the child starts school. These additional services may include general practitioner referral to speech-language pathology or early intervention services (Skeat et al., 2011). Additionally, there is evidence of downstream medical and pharmaceutical costs to the health system, which supports the literature that long-term conditions develop as a by-product of language difficulties. In a recent meta-analyses Yew \& O’Kearney (2013) found that children with language difficulties, compared to those without, are approximately twice as likely to exhibit emotional problems (RR $1 / 41.84 ; 95 \%$ CI $1.04,3.25)$, more than twice as likely to have behavioural difficulties ( $R R \quad 1 / 42.66$; $95 \mathrm{CI}$ $1.66,3.08)$, and are at the 60 th percentile $(95 \% \mathrm{CI}$ 52,68) for ADHD symptoms. (Yew \& O’Kearney, 2013). Further research is required to disentangle the total medical service costs for these children.

Another set of findings is that total healthcare costs for children with language difficulties compared with those without are higher than previous estimates. Sciberras et al. (2015) estimated that the difference in biennial healthcare costs for children with and without language difficulties at age 4-5 was AU\$160 (95\%CI 63, \$257). The estimate from the current study of AU\$AU\$357 (95\%CI \$59, \$659) (Table IV) suggests that this may have been an under estimate. This difference is largely explained by the inclusion of out-of-pocket expenses, which account for AU\$123, or approximately $34 \%$ of the total healthcare cost at this age.

These results improve on previous studies based on cross-sectional analysis alone. The strengths of this study include the use of language measures from a nationally representative longitudinal study with individual linkage to medical, pharmaceutical and hospital expenditure, and calculated out-of-pocket costs. Longitudinal regression techniques were used to examine the costs associated with language difficulties at five time points, from the early childhood, up to when the child is a teenager. Validated and widely used parent report, teacher report, and direct assessments of language difficulties were used, allowing assessment of a broad range of language difficulties.

\section{Limitations}

However, it is acknowledged that one of the difficulties in calculating healthcare utilisation based on language acquisition screening tools is attributing healthcare costs to an additional language healthcare need. Medicare does not provide information about the reason for healthcare attendances and as a result it was not possible to distinguish between services and pharmaceuticals received specifically for the assessment and/or treatment of language difficulties. Several studies have demonstrated that socio-demographic, child and family cultural characteristics play a role in patterns of healthcare utilisation. It is well documented that social disadvantage disparities exist in accessing and utilising healthcare (Fiscella, Franks, Doescher, \& 
Saver, 2002; Flores, Abreu, \& Tomany-Korman, 2005; Flores, Rabke-Verani, Pine, \& Sabharwal, 2002; Flores \& Tomany-Korman, 2008; Yeo, 2004) and children with social disadvantage are at a higher risk of language acquisition and processing difficulties (Fernald, Marchman, \& Weisleder, 2013; Nicholson, Lucas, Berthelsen, \& Wake, 2012) and lower rates of language acquisition growth (Taylor et al., 2013). Children from non-English speaking backgrounds when compared to English speakers have been found to perform poorly on receptive language assessments at early ages but have higher rates of language acquisition growth. Yet their parents are less likely to seek help for their child's difficulties (Cooper, Smaje, \& Arber, 1998; Fiscella et al., 2002; Flores et al., 2005; Flores \& TomanyKorman, 2008; Skeat et al., 2014; Yeo, 2004). While this study has attempted to disentangle the effects of language difficulties and healthcare utilisation through more sophisticated modelling techniques and the inclusion of possible confounders, it is not possible to distinguish between healthcare received specifically for the assessment and/or treatment of language difficulties and health care received to treat co-morbidities or that may be due to factors that are predictors of language difficulties.

A second limitation is how the study was able to define language difficulties at each age. A number of language screening measures are available in LSAC and these vary appropriately to match the developmental age of the child. For example the PPVT-III is a widely accepted screening tool used in longitudinal studies for children between ages 4 and 9 due to it being a cost-effective method with good reliability (Rothman, 2003). However, one of the limitations of these tools is that they provide insufficient detail to allow classification of children as meeting criteria for diagnosed language impairment (Australian Institute of Family Studies, 2013; Centre for Human Resource Research, \& The Ohio State University, 2009). A further limitation is that there is both direct and indirect language screening measures available in the LSAC. For the purposes of this study language difficulties were defined by population standardised scores (25SD below the mean). This produced prevalence estimates of approximately $8.5 \%$ which is consistent with prevalence estimates reported in the literature (Law et al., 2000). Additional supplementary analysis undertaken in this study provided consistent results across language measures. Overall, these findings support healthcare cost differences irrespective of the measure used to define language difficulties.

The LSAC linked Medicare data excludes total service fees for Medicare items. As a result total service fees are calculated as part of the analysis by calculating patient co-payments using published medical services fees from the Australian Medical Association and private health insurance gap schedules from a large private health insurance provider in
Australia (Australian Medical Association (AMA), 2014; Medibank Private, 2014), which introduces some uncertainty in the analysis. As a consistency check we compared the calculated out-of-pocket costs (as a proportion of total healthcare costs) with published AIHW estimates and found that our assumptions are consistent for the population of interest.

It is possible that the analysis is not capturing all of the healthcare costs for these groups. The analysis improves on previous studies with the inclusion of out-of-pocket costs. It captures MBS-funded speech pathology, early intervention services, allied health and speech pathology when accessed through primary care providers. However, there is a ceiling on the number of allied health and speech pathology services that can be claimed under Medicare policy in any calendar year. If families are accessing statefunded community or educationally based providers after exhausting Medicare services, the overall healthcare costs will be underestimated. Equally, it is likely that children from higher income families may access private services which are also not accounted for in these analyses. Further research is required to quantify these additional costs.

\section{Conclusion}

Overall the findings from this study suggest that language difficulties are associated with increased healthcare costs at key developmental milestones, notably early childhood and as a child approaches the teenage years. The results suggest that there is value in implementing effective early intervention to reduce the downstream costs on the health system.

Declaration of interest: The authors report no conflicts of interest. The authors alone are responsible for the content and writing of this article.

\section{References}

Australian Government Department of Health. (2015). Chronic Disease Management (formerly Enhanced Primary Care or EPC) - GP services. Retrieved September 06, 2015 from http:// www.health.gov.au/internet/main/publishing.nsf/content/ mbsprimarycare-chronicdiseasemanagement.

Australian Institute of Family Studies. (2010). Tracking Children's Development Over Time. Retrieved from https:// aifs.gov.au/publications/tracking-childrens-development-overtime/selection-component-variables.

Australian Institute of Family Studies. (2013). Growing up in Australia: The Longitudinal Study of Australian children: Data User Guide. Retrieved from http://www.growingupinaustralia. gov.au/data/docs/userguide/index.html.

Australian Institute of Health and Welfare. (2012). Health Expenditure Australia 2010-11. Health and Welfare expenditure. Canberra: Commonwealth of Australia.

Australian Institute of Health and Welfare (AIHW). (2013). Australia's Health 2014. Retrieved from http://www.aihw.gov. au/australias-health/2014/health-system/. 
Australian Medical Association (AMA). (2014). List of Medical Services and Fees.

Bishop, D.V.M. \& Adams, C. (1990). A prospective study of the relationship between specific language impairment, phonological disorders and reading retardation. Journal of Child Psychology and Psychiatry, 31, 1027-1050. doi:10.1111/j.14697610.1990.tb00844.x.

Buil-Legaz, L., Aguilar-Mediavilla, E., \& Rodríguez-Ferreiro, J. (2016). Oral morphosyntactic competence as a predictor of reading comprehension in children with specific language impairment. International Journal of Language and Communication Disorders, 51, 473-477. doi: 10.1111/14606984.12217.

Center for Human Resource Research, \& The Ohio State University. (2009). National Longitudinal Study of Youth 79Data Users Guide. Bureau of Labor Statistics: U.S. Department of Labor. Retrieved from http://www.nlsinfo.org/pub/usersvc/ Child-Young-Adult/2006ChildYA-DataUsersGuide.pdf.

Clegg, J., Hollis, C., Mawhood, L., \& Rutter, M. (2005). Developmental language disorders-a follow up in later adult life. Cognitive, language and psychosocial outcomes. Journal of Child Psychology and Psychiatry and Allied Disciplines, 46, 128-149. doi:10.1111/j.1469-7610.2004.00342.x.

Community Affairs References Committee. (2014). Prevalence of differenttypes of speech, languageand communicationdisorders and speech pathology services in Australia. Canberra. Retrieved from http://www.aph.gov.au/Parliamentary_Business/Committees/ Senate/Community_Affairs/Speech_Pathology/Report.

Cooper, H., Smaje, C., \& Arber, S. (1998). Use of health services by children and young people according to ethnicity and social class: secondary analysis of a national survey. British Medical Journal (Clinical Research Ed.), 317, 1047-1051. doi:10.1111/ 1460-6984.12217.

Dunn, L., \& Dunn, T. (1997). Peabody Picture Vocabulary Test (3rd Ed.). Circle Pines, MN: American Guidance Services.

Felsenfeld, S., \& Broen, P.A. (1994). A 28-year follow-up of adults with a history of moderate phonological disorder. Journal of Speech and Hearing Research, 37, 1341. doi:10.1044/jshr.3706.1341.

Fernald, A., Marchman, V., \& Weisleder, A. (2013). SES differences in language processing skill and vocabulary are evident at 18 months. Developmental Science, 16, 234-248. doi:10.1111/desc.12019.

Fiscella, K., Franks, P., Doescher, M.P., \& Saver, B.G. (2002). Disparities in health care by race, ethnicity, and language among the insured: Findings from a national sample. Medical Care, 4O, 52-59. doi:10.1097/00005650-200201000-0000.

Flores, G., Abreu, M., \& Tomany-Korman, S.C. (2005). Limited english proficiency, primary language at home, and disparities in children's health care: How language barriers are measured matters. Public Health Reports, 120, 418-430. doi:10.1177/ 003335490512000409.

Flores, G., Rabke-Verani, J., Pine, W., \& Sabharwal, A. (2002). The importance of cultural and linguistic issues in the emergency care of children. Pediatric Emergency Care, 18, 271-284. doi:10.1097/00006565-200208000-00010.

Flores, G., \& Tomany-Korman, S.C. (2008). The language spoken at home and disparities in medical and dental health, access to care, and use of services in US children. Pediatrics, 121, e1703-e1714. doi:10.1542/peds.2007-2906.

Law, J., Boyle, J., Harris, F., Harkness, A., \& Nye, C. (2000). Prevalence and natural history of primary speech and language delay: findings of a systematic review of the literature. International Journal of Language and Communication Disorders, 35, 165-188.

Leitao, S., \& Fletcher, J. (2004). Literacy outcomes for students with speech impairment: Long-term follow-up. International Journal of Language \& Communication Disorder, 39, 245-256. doi:10.1080/13682820310001619478.

Lewis, B.A., Freebairn, L., Tag, J., Ciesla, A.A., Iyengar, S.K., Stein, C.M., \& Taylor, H. (2015). Adolescent outcomes of children with early speech sound disorders with and without language impairment. American Journal of SpeechLanguage Pathology, 24, 150-163. doi:10.1044/2014_AJSLP14-0075.

McLeod, S. \& Harrison, L.J. (2009). Epidemiology of speech and language impairment in a nationally representative sample of 4- to 5 -year-old children. Journal of Speech, Language, and Hearing Research, 52, 1213-1229. doi:10.1044/10924388(2009/08-0085).

McLeod, S. \& McKinnon, D.H. (2007). Prevalence of communication disorders compared with other learning needs in 14,500 primary and secondary school students. International Journal of Language and Communication Disorders, 42, 37-59. doi:10.1080/13682820601173262.

Medibank Private. (2014). Medibank Private Gapcover. Retrieved from http://www.medibank.com.au/providers/gap-cover/.

Nicholson, J.M., Lucas, N., Berthelsen, D., \& Wake, M. (2012). Socioeconomic inequality profiles in physical and developmental health from 0-7 years: Australian National Study. Journal of Epidemiology and Community Health, 66, 81-87. doi:10.1136/jech.2009.103291.

Reilly, S., Tomblin, B., Law, J., McKean, C., Mensah, F.K., Morgan, A ... Wake, M. (2014). Specific language impairment: A convenient label for whom? International Journal of Language and Communication Disorder, 49, 416-451. doi: 10.1111/1460-6984.12102.

Reilly, S., Wake, M., Ukoumunne, O., Bavin, E.L., Prior, M., Cini, E .. . Bretherton, L. (2010). Predicting language outcomes at 4 years of age: Findings from early language in victoria study. Pediatrics, 126, e1530-e1537. doi:10.1542/ peds.2010-0254.

Rice, M.L., Slegers, D.W., Taylor, C.L., \& Zubrick, S.R. (2007). Late language emergence at 24 months: An epidemiological study of prevalence, predictors, and covariates. Journal of Speech Language and Hearing Research, 50, 156. doi:10.1044/ 1092-4388(2007/106).

Rothman, S. (2003). AnAustralianversion of the adapted PPVT-III for use in research. Melbourne: Australian Council for Educational Research.

Roy, P., \& Chiat, S. (2013). Teasing apart disadvantage from disorder: the case of poor language. In: C. R. Marshall (Ed.), Current Issues in Developmental Disorders (pp. 125-150). New York: Pschology Press.

Ruben, R.J. (2000). Redefining the survival of the fittest: communication disorders in the 21 st century. Laryngoscope, 110, 241-245. doi:10.1097/00005537-200002010-00010.

Sanson, A., Nicholson, J.M., Ungerer, J., Zubrick, S.R., Wilson, K., Ainley, J., ... Wake, M. (2002). Introducing the Longitudinal Study of Australian Children. Australian Institute of Family Studies. Retrieved from http://www.growingupinaustralia.gov.au/pubs/discussion/dp1/index.html.

Schoon, I., Parsons, S., Rush, R., \& Law, J. (2010). Childhood language skills and adult literacy: A 29 year follow-up study. Pediatrics, 125, 459-466. doi:10.1542/peds.2008-2111.

Sciberras, E., Westrupp, E., Wake, M., Nicholson, J.M., Lucas, N., Mensah, F.K .. . Reilly, S. (2015). Healthcare costs associated with language difficulties up to 9 years of age: Australian population-based study. International Journal of Speech-Language Pathology, 17, 41-52. doi:10.3109/ 17549507.2014.898095.

Skeat, J., Gold, L., Wake, M., Ukoumunne, O.C., \& Reilly, S. (2011). The costs of preschool communication problems. The Medical Journal of Australia, 195, 322-323. doi:10.5694/ mja11.10254.

Skeat, J., Wake, M., Ukoumunne, O.C., Eadie, P., Bretherton, L., \& Reilly, S. (2014). Who gets help for pre-school communication problems? data from a prospective community study. Child: Care Health \& Development, 40, 215-222. doi:10.1111/ cch.12032] [23521127.

Taylor, C.L., Christensen, D., Lawrence, D., Mitrou, F., \& Zubrick, S.R. (2013). Risk factors for children's receptive vocabulary development from four to eight years in the 
longitudinal study of Australian children. PloS One, 8, e73046. doi:10.1371/journal.pone.0073046.

Tomblin, J.B., Records, N.L., Buckwalter, P., Zhang, X. Smith, E., \& O'brien, M. (1997). Prevalence of specific language impairment in kindergarten children. Journal of Speech Languange \& Hearing Research, 40, 1245-1260. doi:10.1044/jslhr.4006.1245.
Yeo, S. (2004). Language barriers and access to care. Annual Review Nursing Research, 22, 59-73.

Yew, S., \& O'kearney, R. (2013). Emotional and behavioural outcomes later in childhood and adolescence for children with specific language impairments: Meta-analyses of controlled prospective studies. Journal of Child Psychology and Psychiatry, 54, 516-524. doi:10.1111/jcpp.12009. 